\title{
BMJ Open Stigma towards mental illness among medical and nursing students in Singapore: a cross-sectional study
}

\author{
Sherilyn Chang, ${ }^{1}$ Hui Lin Ong, ${ }^{1}$ Esmond Seow, ${ }^{1}$ Boon Yiang Chua, \\ Edimansyah Abdin, ${ }^{1}$ Ellaisha Samari, ${ }^{1}$ Wen Lin Teh, ${ }^{1}$ Siow Ann Chong, ${ }^{1}$ \\ Mythily Subramaniam²
}

\begin{abstract}
To cite: Chang S, Ong HL, Seow E, et al. Stigma towards mental illness among medical and nursing students in Singapore: a crosssectional study. BMJ Open 2017;7:e018099. doi:10.1136/ bmjopen-2017-018099

- Prepublication history for this paper is available online. To view these files, please visit the journal online (http://dx.doi. org/10.1136/bmjopen-2017018099).
\end{abstract}

SC and HLO contributed equally.

Received 6 June 2017

Revised 17 October 2017

Accepted 3 November 2017

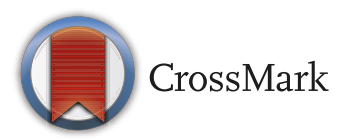

${ }^{1}$ Research Division, Institute of Mental Health, Singapore, Singapore

${ }^{2}$ Research Division, Institute of Mental Health, Singapore, Singapore

\section{Correspondence to}

Sherilyn Chang;

sherilyn_sh_chang@imh.com. $\mathrm{sg}$

\section{ABSTRACT}

Objectives To assess stigma towards people with mental illness among Singapore medical and nursing students using the Opening Minds Stigma Scale for Health Care Providers (OMS-HC), and to examine the relationship of students' stigmatising attitudes with sociodemographic and education factors.

Design and setting Cross-sectional study conducted in Singapore

Participants The study was conducted among 1002 healthcare (502 medical and 500 nursing) students during April to September 2016. Students had to be Singapore citizens or permanent residents and enrolled in public educational institutions to be included in the study. The mean (SD) age of the participants was 21.3 (3.3) years, with the majority being females $(71.1 \%) .75 .2 \%$ of the participants were Chinese, $14.1 \%$ were Malays, and $10.7 \%$ were either Indians or of other ethnicity. Methods Factor analysis was conducted to validate the OMS-HC scale in the study sample and to examine its factor structure. Descriptive statistics and multivariate linear regression were used to examine sociodemographic and education correlates.

Results Factor analysis revealed a three-factor structure with 14 items. The factors were labelled as attitudes towards help-seeking and people with mental illness, social distance and disclosure. Multivariable linear regression analysis showed that medical students were found to be associated with lower total OMS-HC scores $(P<0.05)$, less negative attitudes $(P<0.001)$ and greater disclosure $(\mathrm{P}<0.05)$ than nursing students. Students who had a monthly household income of below $\$ \$ 4000$ had more unfavourable attitudes than those with an income of SGD\$10 000 and above $(P<0.05)$. Having attended clinical placement was associated with more negative attitudes $(\mathrm{P}<0.05)$ among the students.

Conclusion Healthcare students generally possessed positive attitudes towards help-seeking and persons with mental illness, though they preferred not to disclose their own mental health condition. Academic curriculum may need to enhance the component of mental health training, particularly on reducing stigma in certain groups of students.

\section{INTRODUCTION}

Stigma is defined as 'a mark of shame, disgrace or disapproval that results in an individual

\section{Strengths and limitations of this study}

This is the first study that validated the Opening Minds Stigma Scale for Health Care Providers for use in an Asian healthcare student population.

- Students' stigma towards persons with mental illness were assessed.

- Large sample size and participants were recruited from multiple medical and nursing institutions in Singapore, which strengthens the generalisability of findings.

- Cross-sectional study design limits the ability to draw causal conclusions.

being rejected, discriminated against and excluded from participating in a number of different areas of society'. ${ }^{1}$ The study of stigma in the area of mental illness has been gaining importance in recent years. Current research on mental illness stigma is mainly focused on public stigma towards individuals with mental illness, ${ }^{2-4}$ interventions to reduce mental illness stigma among students ${ }^{5-7}$ and how mental illness stigma would affect helpseeking and treatment engagement among patients with mental illness. ${ }^{89}$ Studies have found that individuals who are older and have lower education possess more negative attitudes towards persons who are mentally $\mathrm{ill}^{2}{ }^{3}$; clinical placements ${ }^{10}$ and antistigma training ${ }^{11}$ were effective in reducing mental illness stigma in students; individuals who sought help for mental illness often report that they encountered stigmatising attitudes from healthcare providers, ${ }^{12}{ }^{13}$ and these acted as barriers to quality care and treatment, subsequently affecting their recovery due to the feeling of being 'patronised, punished or humiliated' in their interactions with healthcare providers. ${ }^{145}$

Various research studies have documented stigmatising attitudes of healthcare providers and of the general population towards those 
with mental illness in Singapore, ${ }^{3}$ Czech Republic ${ }^{16}$ and Australia. ${ }^{17}$ Compared with the general population, medical doctors in Czech Republic demonstrated more favourable attitudes towards people with mental illness. Mental health professionals in Australia possess less stigmatising attitudes towards persons with mental illness than the general public. ${ }^{1617}$ The difference could be attributed to better knowledge of mental illness by the professionals and explained by the contact hypothesis which states that increased personal and professional contact with people with mental illness is associated with more positive attitudes and reduced stigmatisation towards them. ${ }^{18-20}$ Other studies, however, found contradicting results where higher level of stigma was reported among healthcare providers than in the general population. ${ }^{132122}$

To explain why some healthcare providers have higher level of stigma towards persons with mental illness, Thornicroft $e t \mathrm{al}^{12}$ suggested that despite having more contact with persons with mental illness, healthcare providers could be influenced by physician bias, where mental healthcare providers tend to base their attitudes on their clinical experience of treating people with mental health problems. ${ }^{12}$ For example, in a mental healthcare setting, psychiatrists and nurses are more likely to be attending to patients who have not recovered or are suffering from relapse, as compared with seeing patients who have recovered. ${ }^{12}$ Thus, with these poor outcomes in mind, persons with mental illness may not receive similar care from healthcare providers once these providers become aware of the 'severity' of patient's mental health conditions. ${ }^{4}{ }^{23}$ Hence, in view of the aforementioned theories which suggest that contact with psychiatric patients would either way influence healthcare providers' attitudes towards their patients, it is thus crucial to understand potential stigmatising attitudes held by healthcare providers as it could affect their care practices for these patients. ${ }^{24}$

Most of the aforementioned studies included intervention studies which measured the impact of educational initiatives on attitudes ${ }^{10} 25$ and cross-sectional studies that used scales to measure attitudes and stigma towards people with mental illness among healthcare professionals and in the general population. ${ }^{26-28}$ Fewer studies have looked at attitudes among medical and nursing students, who are the future doctors and nurses of the community. Kassam et $a l^{26}$ assessed medical students' attitudes towards people with mental illness using the Mental Illness: Clinicians' Attitudes scale and found significant ethnic groups differences but no differences between medical specialities. In another study conducted in Canada, Kassam et $a l^{27}$ compared different professional groups including 'physicians and medical student' and 'psychiatric nurses and psychiatric nursing students' and found that they had more stigmatising attitudes than social workers. A few other cross-sectional studies have also compared attitudes towards mental illness between medical and nursing students in India, ${ }^{29}$ nursing students in Sweden and India, ${ }^{30} 31$ and medical students in Nigeria and Sri Lanka. ${ }^{32} 33$

Despite the substantial research conducted with students at an international level, little is known about attitudes towards individuals with mental illness in Asian countries such as Singapore. ${ }^{34}$ Singapore is a multiethnic country that comprises $74.3 \%$ Chinese, $13.4 \%$ Malays, $9.1 \%$ Indians and $3.2 \%$ of other ethnicity group. ${ }^{35}$ Given that attitudes differ across ethnic groups ${ }^{236}$ and healthcare specialisations, ${ }^{37}$ it is crucial to examine medical and nursing students' attitudes towards persons with mental illness in Singapore, who are the future doctors and nurses of the local community. Thus in this paper, the aim was to broaden the current understanding of healthcare (medical and nursing) students' attitudes towards persons with mental illness by (1) examining and comparing responses of healthcare students using the Opening Minds Stigma Scale for Health Care Providers (OMS-HC) scale and (2) assessing the relationship between sociodemographic and education factors with the OMS-HC scores.

\section{METHOD}

\section{Design and sample}

This cross-sectional study used an online web survey, QuestionPro, to collect data from Singapore's medical and nursing students. Ethics approval was given by the National Healthcare Group's Domain Specific Review Board, Singapore. The target population included medical and nursing students who were enrolled in public medical and nursing educational programmes in Singapore during the study recruiment period from April to September 2016. Students were invited to take part in the web survey through school email or verbal dissemination by staff representative. Students who were Singapore residents (citizens or permanent residents) were eligible to participate in the study. Participants would need to accept and agree to an online informed consent document before they could proceed to complete the survey. On completion of the study, participants would receive a Starbucks card as an inconvenice fee.

\section{Instruments}

The instruments used in this study comprised a self-report questionnaire that included questions on sociodemographic details such as age, gender, ethnicity, average monthly household income for the past 1 year as well as the course that they were enrolled in (ie, medicine or nursing), school academic year and whether they had attended clinical placement in psychiatry or psychiatric nursing in their school curriculum.

\section{Opening Minds Stigma Scale for Health Care Providers}

The current study adopted the 15-item OMS-HC to measure healthcare students' attitudes towards persons with mental illness. ${ }^{37}$ The original version of the OMS-HC scale comprised 20 items and was originally developed by 
Kassam et al. ${ }^{27}$ The scale was then reduced to 15 items due to low item-total correlations $(r<0.20)$ and cross-loading found in five items in another study that was conducted among healthcare providers such as physicians, social workers, and medical and nursing students. The 15-item scale and subscales were reported to have a high level of internal consistency $(\alpha=0.74-0.79$ and $\alpha=0.67-0.68$, respectively). ${ }^{37}$ The scale is rated on a five-point Likert scale with scores ranging from 1 (strongly disagree) to 5 (strongly agree). The total scores range from 15 to 75 , and lower scores indicate less stigmatising attitude. Questions include, for example, 'If a colleague with whom I work told me they had a managed mental illness, I would be just as willing to work with him/her' (item 3) and 'More than half of people with mental illness don't try hard enough to get better' (item 14). The 15-item OMS-HC was proposed to cover three components: attitudes towards people with mental illness, disclosure/help-seeking and social distance. Items that required reverse coding were recoded, and total score was calculated by taking the sum of raw scores for the 15 items. Subscale scores were calculated by summing the raw scores of all items in each factor. ${ }^{37}$ Higher scores for each factor indicated a more negative attitude, less disclosure and greater social distance between persons with mental illness accordingly.

\section{Statistical analyses}

Participants' responses to the survey were coded and entered into the SPSS V.23.0. The frequency and percentage of subjects were calculated for categorical variables, and mean and $\mathrm{SD}$ were calculated for continuous variables.

The factor structure was determined by several steps. First, confirmatory factor analysis (CFA) was conducted to test the three-factor structure of 15-item OMHS-HC from the previous study. ${ }^{37}$ However, the model fit indices suggested that the 15-item models did not fit into our data. Therefore, exploratory factor analysis (EFA) was conducted to explore the factor structure using Mplus V.7.4. Kaiser-Meyer-Olkin (KMO) measure of sampling adequacy test and Bartlett's test of sphericity were conducted to assess the suitability of the data for factor models. The number of factors retained were determined based on eigenvalues $>1.0$, scree plot and parallel analysis. ${ }^{38}$ To account for possible correlation between the factors, oblique rotation (direct oblimin) was used to clarify the factor structure. Item loadings were analysed and those with a loading $>0.3$ were retained for a specific factor. ${ }^{39}$ An exploratory structural equation modelling (ESEM), which is an integration of EFA, CFA and SEM in a single framework, ${ }^{40}$ was then carried out. The ESEM offers the same advantages as CFA analysis in terms of fit indexes, SEs and tests of significance, and is able to freely estimate all rotated cross-loadings between indicators and latent factors as with EFA. Moreover, the ESEM framework's flexibility (correlated residuals and tests of invariance) provides a synergy between CFA, EFA and SEM. $^{42}$ The internal consistency for the OMS-HC scale and subscales were evaluated using the Cronbach's alpha coefficient.

Levels of agreement and disagreement to each of the OMS-HC statements were combined such that 'strongly disagree' and 'disagree' responses were grouped as a single 'disagree' category, and 'strongly agree' and 'agree' responses were grouped as a single 'agree' response outcome. Response categories were thus reduced from five outcomes to three outcomes (disagree, neutral and agree) and examined. One-way analysis of variance (ANOVA) and t-tests were used to assess group differences in OMS-HC total score across sociodemographic variables. Multivariable linear regression was then conducted to examine these differences while accounting for potential confounders. Sociodemographic variables (ie, age, gender, ethnicity and average monthly household incomes), student group, school academic year and status of clinical placement were included as independent variables in the regression. Total OMS-HC score and subscale scores were dependent variables in each of the regression models. All statistically significant results were reported at $\mathrm{P} \leq 0.05$.

\section{RESULTS}

\section{Sample characteristics}

A total of 1002 healthcare students were recruited for this study, of which 502 were medical students and 500 were nursing students. The overall mean age was 21.3 years $(\mathrm{SD}=3.3)$. Table 1 presents the profile of the study sample. The majority of the participants were female $(71.1 \%)$ and of Chinese ethnicity (75.2\%). Most of the participants were in their first $(30.7 \%)$ and second $(30.9 \%)$ year of study. The sample consisted of an almost equal proportion of students who had not attended clinical placement versus those who had attended it (50.9\% vs $49.1 \%)$.

\section{Factor structure}

CFA was performed and results from the Root Mean Square Error of Approximation (RMSEA), Comparative Fit Index (CFI) and Tucker Lewis Index (TLI)suggested that the original three-factor model by Modgill et $a \vec{l}^{37}$ had poor fit to the current sample (RMSEA $=0.096$, CFI $=0.838$, TLI $=0.804)$. An EFA was then performed to explore the factor structure of the 15-item OMS-HC that was suited for the current sample. In this study, the KMO value was 0.799 and the Bartlett's test was significant; therefore, a factor analysis of the OMS-HC scale was appropriate ${ }^{43}$ Eigenvalue $>1$, scree plot and parallel analysis results suggested a threefactor structure that was similar to the one proposed by Modgill $e t a l^{77}$ in their validation study of the OMS-HC scale, but with slight differences in item loadings. Based on the factor loading cut-off of 0.3 , results showed that one item ('I would not want a person with a mental illness, even if it were appropriately managed, to work with children'; item 17) had cross-loadings on factor 1 and factor 2 (table 2). The item had a higher loading on factor 1 and was thus retained in that factor for subsequent analysis. 


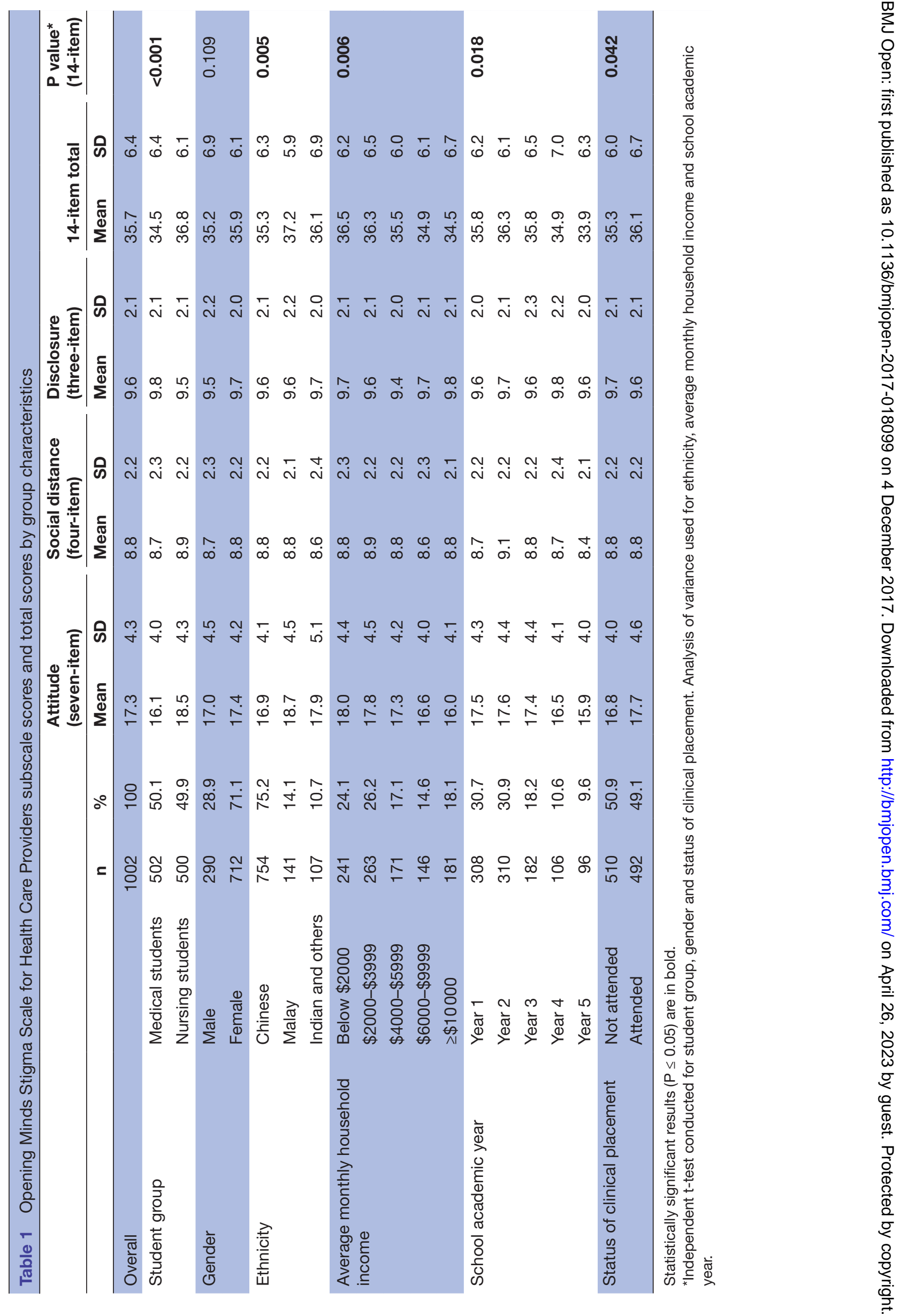


Table 2 Factor structure of the 14-item version $(n=1002)$

\begin{tabular}{|c|c|c|c|c|}
\hline & \multicolumn{3}{|l|}{ Factor* } & \multirow{2}{*}{$\begin{array}{l}\text { Alpha if } \\
\text { deleted }\end{array}$} \\
\hline & 1 & 2 & 3 & \\
\hline \multicolumn{5}{|l|}{ Factor 1: attitudes towards help-seeking and people with mental illness } \\
\hline $\begin{array}{l}\text { Despite my professional beliefs, I have negative reactions towards people who } \\
\text { have mental illness (item 12). }\end{array}$ & 0.458 & 0.256 & 0.101 & 0.719 \\
\hline $\begin{array}{l}\text { I would not want a person with a mental illness, even if it were appropriately } \\
\text { managed, to work with children (item 17). }\end{array}$ & 0.382 & 0.361 & 0.012 & 0.716 \\
\hline $\begin{array}{l}\text { Healthcare providers do not need to be advocates for people with mental illness } \\
\text { (item 18). }\end{array}$ & 0.582 & 0.077 & -0.147 & 0.723 \\
\hline $\begin{array}{l}\text { If a colleague with whom I work told me they had a managed mental illness, I } \\
\text { would be as willing to work with him/her (item } 3 \text { ). }\end{array}$ & 0.016 & 0.651 & -0.144 & 0.732 \\
\hline $\begin{array}{l}\text { Employers should hire a person with a managed mental illness if he/she is the } \\
\text { best person for the job }{ }^{2} \text { (item 8). }\end{array}$ & -0.002 & 0.489 & -0.255 & 0.740 \\
\hline $\begin{array}{l}\text { I would still go to a physician if I knew that the physician had been treated for a } \\
\text { mental illness }{ }^{2} \text { (item 9). }\end{array}$ & -0.146 & 0.663 & -0.013 & 0.740 \\
\hline I would not mind if a person with a mental illness lived next door to me ${ }^{2}$ (item 19). & 0.049 & 0.568 & 0.053 & 0.731 \\
\hline \multicolumn{5}{|l|}{ Factor 3: disclosure } \\
\hline $\begin{array}{l}\text { If I were under treatment for a mental illness I would not disclose this to any of my } \\
\text { colleagues (item 4). }\end{array}$ & 0.275 & 0.024 & 0.666 & 0.747 \\
\hline
\end{tabular}

Highest factor loading of each item across the three factors are highlighted in bold.

*Using exploratory structural equation mode; $I^{2}$ reverse scored; items are numbered following the original scale from Modgill et $\mathrm{a} \mathrm{l}^{37}$.

Additionally, an item ('I am more comfortable helping a person who has a physical illness than I am helping a person who has a mental illness'; item 1) had poor loading $(<0.3)$ across all three factors and was removed from the analysis. The final OMS-HC used for subsequent analysis consisted of 14 items with three extracted factors. The model also fit the data well (RMSEA $=0.069, \mathrm{CFI}=0.948$, $\mathrm{TLI}=0.909$ ). The three factors extracted were labelled as attitudes towards help-seeking and people with mental illness (factor 1, seven items), social distance (factor 2, four items) and disclosure (factor 3, three items). The items demonstrated an acceptable level of internal consistency with Cronbach's alpha value of 0.75 for the overall 14-item scale and $0.74,0.60$ and 0.53 , respectively, for each factor.

\section{OMS-HC total and subscale scores}

The 14-item OMS-HC total possible scores range from 14 to 70 with lower scores indicating less stigmatising attitude. For the subscale scores, the possible range of scores are 7-35 (attitudes), 4-20 (social distance), and 3-15 (disclosure). The mean score for the 14-item OMS-HC in this study was $35.7(\mathrm{SD}=6.4)$, and the subscale scores for attitudes, social distance and disclosure were 17.3 $(\mathrm{SD}=4.3), 8.8(\mathrm{SD}=2.2)$ and $9.6(\mathrm{SD}=2.1)$, respectively. Medical students scored a mean of $34.5(\mathrm{SD}=6.4)$ for the 14-item OMS-HC, and nursing students had a mean score of $36.8(\mathrm{SD}=6.1)$. Stratification of scores by sociodemographic variables is presented in table 1.

\section{OMS-HC item responses}

Attitudes towards help-seeking and people with mental illness

Levels of agreement to each of the OMS-HC statements are provided in table 3 and are grouped according to overall responses, responses from medical students and responses from nursing students. Responses from the attitudes subscale revealed that healthcare students in this sample generally had positive attitudes towards individuals with mental illness, although some differences between medical and nursing students exist. Majority of the students disagreed with statements reflecting negative attitudes towards individuals with mental illness, with overall level of disagreement ranging from $45.1 \%$ to $67.7 \%$. However, across six items in this subscale, there was a higher percentage of nursing students than medical 


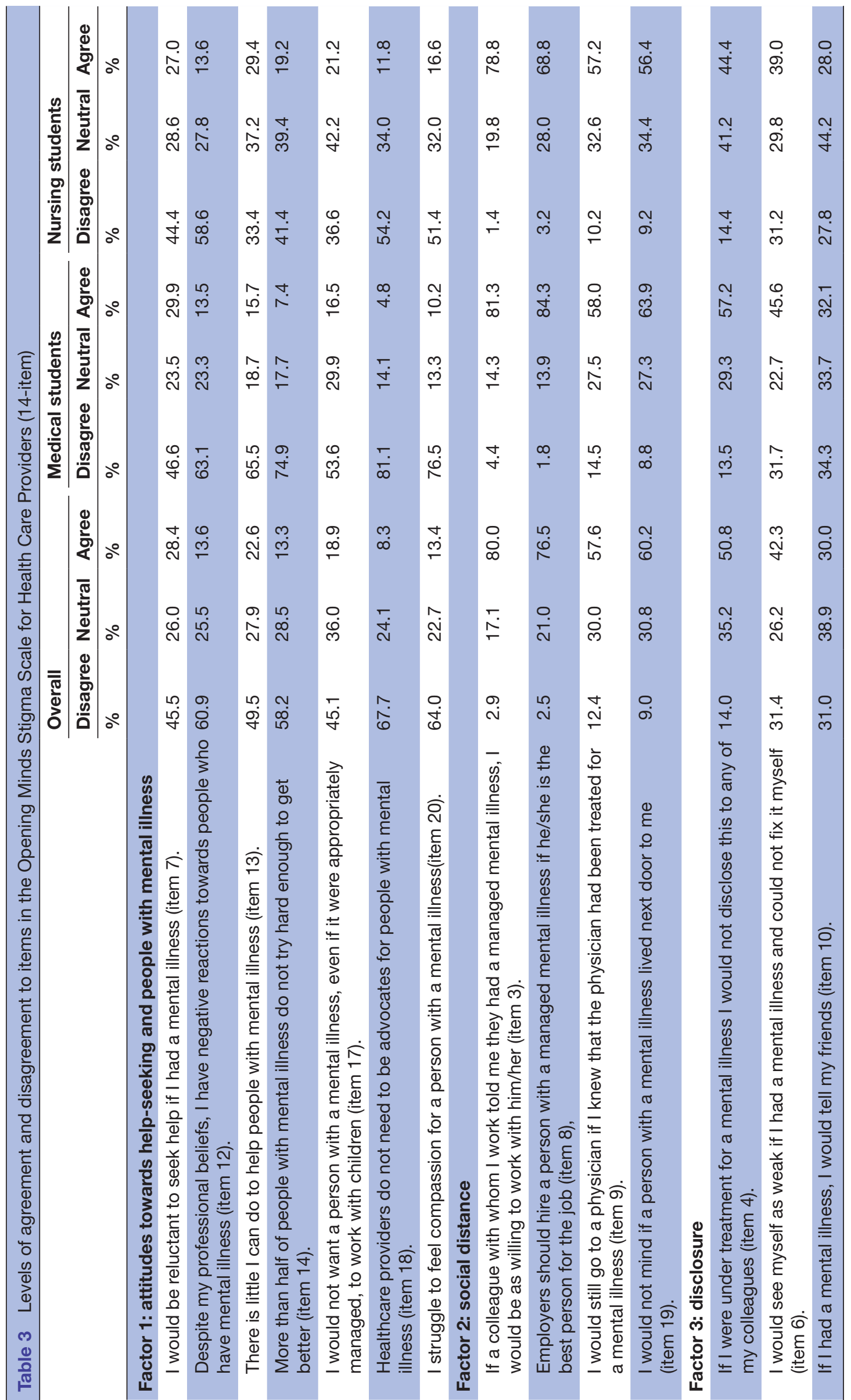


students who agreed with the statements depicting negative attitudes. Nursing students, as compared with medical students, were more likely to agree with statements such as 'There is little I can do to help people with mental illness' (item 13; $29.4 \%$ vs $15.7 \%$ ) and 'More than half of people with mental illness don't try hard enough to get better' (item 14; $19.2 \%$ vs $7.4 \%$ ). There was a slightly higher percentage of medical students who agreed that they 'would be reluctant to seek help if I [they] had a mental illness' (item 7; $29.9 \%$ vs $27.0 \%$ ). Overall, more than a quarter of healthcare students $(28.4 \%)$ stated that they would be reluctant to seek help.

\section{Social distance}

The overall level of agreement with statements reflecting positive behavioural intentions towards persons with mental illness in the social distance subscale ranged from $57.6 \%$ to $80.0 \%$. A large majority of the students agreed that they 'would be as willing to work with a colleague with managed mental illness' (item 3; overall 80.0\%), though only slightly more than half the students agreed that they 'would still go to a physician if he/she had been treated for mental illness' (item 9; overall 57.6\%). Comparing the responses between medical students and nursing students, the latter had lower levels of agreement across all the positive items, indicating greater social distance towards persons with mental illness.

\section{Disclosure}

Most of the students would not disclose their own mental illness to their colleagues (item 4; overall, 50.8\%) and agreed with the statement that 'I would see myself as weak if I had a mental illness and could not fix it myself' (item 6; overall, 42.3\%). Medical students as compared with nursing students had a higher level of agreement to the statement regarding non-disclosure of mental illness to their colleague (item $4 ; 57.2 \%$ vs $44.4 \%$ ). A larger percentage of medical students also agreed that having a mental illness, which they could not resolve by themselves, is a form of weakness (item $6 ; 45.6 \%$ vs $39.0 \%$ ).

\section{Correlates of OMS-HC scores}

Several variables were significantly associated with OMS-HC total score at the univariate level including student group, ethnicity, average monthly household income, school academic year and status of clinical placement (table 1).

However, when controlled for other sociodemographic and education variables, many of these associations no longer remained significant. Table 4 shows the multivariable regression analysis of OMS-HC and subscales scores. Results showed that medical students had lower OMS-HC total score $(\mathrm{B}=-1.375, \mathrm{P}<0.05)$, lower attitudes subscale score $(\mathrm{B}=-1.702, \mathrm{P}<0.001)$ and higher disclosure subscale score $(\mathrm{B}=0.429, \mathrm{P}<0.05)$ compared with nursing students. Lower monthly household income was independently associated with higher attitudes subscale score. Compared with those with an average monthly household income of SGD $\$ 10000$ and above, participants with a household income of below SGD $\$ 2000(\mathrm{~B}=1.180, \mathrm{P}<0.01)$ and those with SGD\$2000-SGD\$3999 $(\mathrm{B}=0.981, \mathrm{P}<0.05)$ had higher attitudes subscale score. Students who had not attended clinical placement had lower attitudes subscale score compared with those who had attended placement $(\mathrm{B}=-0.799, \mathrm{P}<0.05)$.

\section{DISCUSSION}

In this study, we have utilised the OMS-HC scale to explore healthcare students' attitudes towards persons with mental illness. The similar three-factor structure obtained suggests that the components of stigma, namely attitudes towards help-seeking and people with mental illness, disclosure and social distance, are likely to be comparable between healthcare students and professionals in Canada $^{37}$ and healthcare students in Singapore. To allow for comparison of scores between the Canadian study sample ${ }^{37}$ - which included both healthcare students and professionals-and the sample from the current study, a 15-item OMS-HC score was calculated. The former had a sample mean of 33.4, while the mean of the current study sample was 39.0; Canadian medical students scored a mean of 34.2 on the 15-item OMS-HC scale, while the medical students from this study had a mean of 38.1.

Despite having higher scores than the Canadian sample, the majority of healthcare students in the present study generally hold positive attitudes towards individuals with mental illness. Responses on the attitudes subscale showed that most students disagreed with statements reflecting negative attitudes. Interestingly, close to one-fifth of the students agreed that they would not want an individual with mental illness, even if it was a managed condition, to work with children. More than a third of the students had mixed views on this. It may have been due to the perception that psychiatric patients are 'dangerous' and 'unpredictable', an association that had been reported in previous stigma studies, ${ }^{3445}$ and thus the reluctance among students in having persons with mental illness work with children who are usually deemed as a vulnerable group. Additionally, a difference emerged between medical students and nursing students in response to the statement 'There is little I can do to help people with mental illness'. While the majority of medical students disagreed with the statement $(65.5 \%)$, nursing students were twice more likely to agree with the statement $(29.4 \%$ vs $15.7 \%$ ). This is in line with results reported by Cleary and Dowling ${ }^{46}$ where they found that nursing staff had poorer understanding of their role and responsibilities in the recovery of mental health patients as compared with non-nursing staff. This could be attributed to a lack of empowerment among nurses wherein it is traditionally viewed that nurses take on a 'care' role, while doctors are involved in the 'cure' component, ${ }^{47}$ thus nursing students perceived lesser contribution that they could make in the recovery of patients. Twice the proportion of nursing student as compared with medical students agreed with 


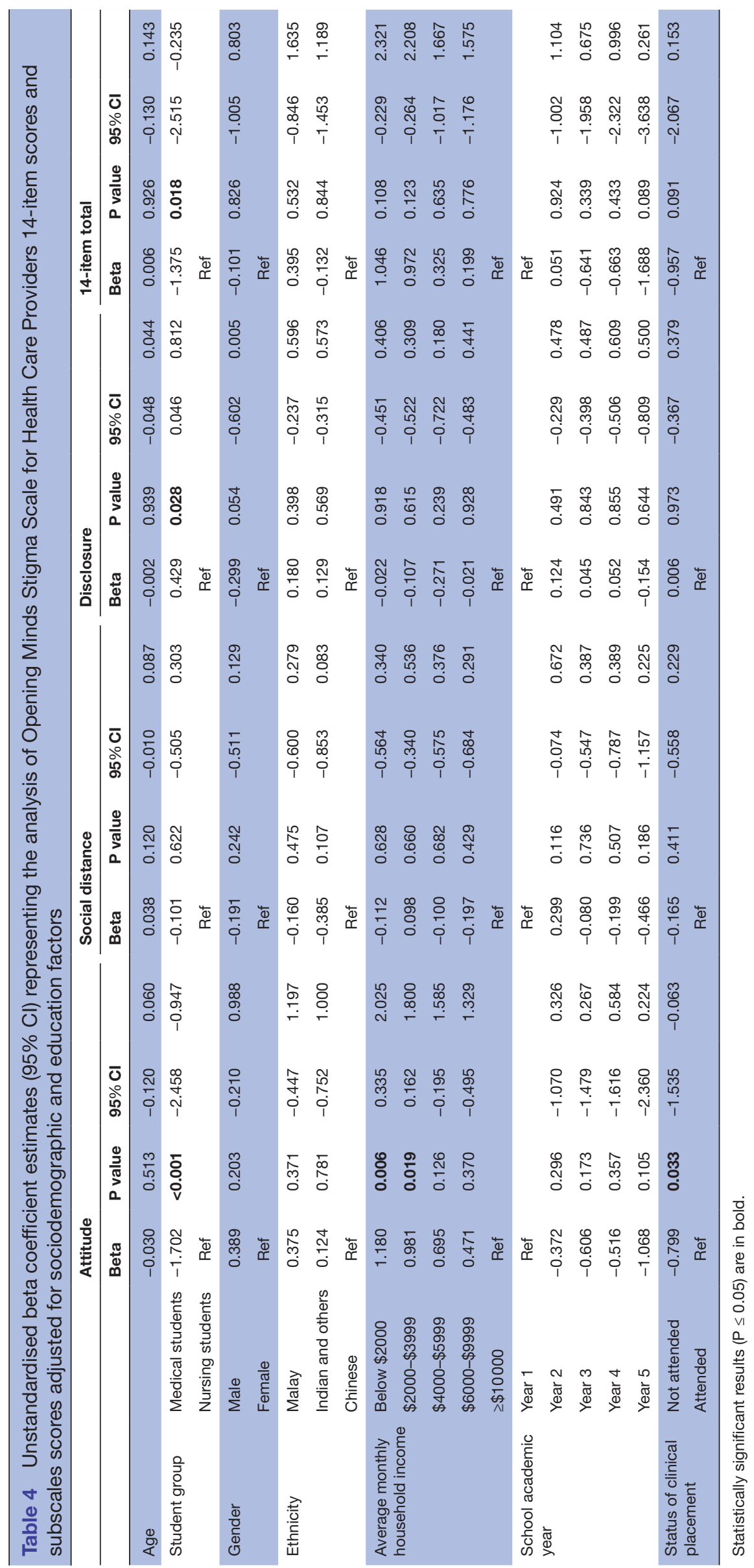


the statement that people with mental illness 'don't try hard enough to get better' $(19.2 \%$ vs $7.4 \%)$. It may be that nursing students are more likely to attribute psychiatric illness to social and personal factors, and less likely to biological factors as what doctors do $;^{48}$ thus, they perceive mental illness as controllable if patients 'try harder'.

Although the majority of healthcare students would seek help for mental health problems, a sizeable proportion $(28.4 \%)$ were reluctant to do so. This is a cause for concern and is worth further examination as these students are future healthcare professionals who ought to encourage those in the general community who have ailments to seek the appropriate treatment, and untreated mental health problems among healthcare professionals might possibly affect their ability to tend to their patients effectively and safely. Responses from the OMS-HC instrument suggest that it may have been the association of mental illness with personal weakness that precedes the reluctance to seek help.

Compared with the other two factors, items from the factor on disclosure received more ambivalent responses from the healthcare students. The majority perceived having a mental illness as a character flaw and a weakness if it cannot be resolved by one's own will. This reflects similar sentiments as that held by the general community that mental illness is a 'weakness' and not a 'sickness'. ${ }^{17}$ Healthcare students in this study were more likely to not disclose any personal mental health issues to their colleagues. This might have been associated with a fear of the implications on job prospects and a perceived lack of support. ${ }^{49-52}$ A study by Gras $e t a t^{28}$ also found that the most stigmatising attitudes among healthcare professionals were their views on disclosure.

Several correlates of OMS-HC scores were identified in this study. First, being a medical student was associated with less negative attitudes as compared with nursing students. There are limited studies that directly compare stigma levels and attitudes in these two groups of students; hence, it is difficult to draw a conclusion. However, it is plausible that the differences in training and education received by a medical student and a nursing student gave rise to this observed difference. This might also suggest a need to enhance anti-stigma campaigns that are incorporated in the education of healthcare professionals, particularly interventions that are aimed at improving attitudes among nursing students. The second correlate found was income whereby students with lower monthly household income had higher attitudes subscale score (ie, greater negative attitudes). Given that the participants were students and thus unlikely to contribute to their household income, it may be assumed that the source of income was mostly from their parents or siblings. This finding supports what has been reported in the literature that a lower socioeconomic status was associated with higher perceived stigma among students ${ }^{53}$ and in the general population. ${ }^{23}$ This may be indicative of a poorer learning environment in the family in terms of knowledge and awareness of mental health issues, and thus a less tolerant attitude towards mental illness. As such, it could have influenced the beliefs of the students, which was reflected as negative attitudes towards persons with mental illness.

Our study found that students who had attended clinical placement had higher OMS-HC attitude subscale scores (ie, more stigmatising attitudes) as compared with students who had not attended such placement. It is plausible that for the purpose of a steeper learning curve in the short attachment stint, students who went for clinical attachments had been in contact with patients who had more severe and chronic symptoms, and this could have contributed to their negative attitudes towards mental illness. This finding is in contrast with several studies in the literature that found a positive shift in attitudes after clinical attachments. ${ }^{10} 5455$ It is worth noting that the quality of the clinical experience, including clinical placement duration, provision of faculty support and an active involvement in patient care have an impact on the changes in attitudes. ${ }^{10} 5657$ A study by Moxham $e t a \tilde{l}$ found that the type of clinical placement attended affects students' level of stigma; nursing students who attended non-traditional clinical placement (conducted outside a clinical setting and involved different types of learning activities) showed greater stigma reduction than those who attended 'typical' clinical placement (ie, hospital-based settings). However, the quality of clinical attachment was not assessed in the present study and thus needs further exploration in future studies.

The following limitations should be considered when interpreting the above findings. The study employed a cross-sectional study design; thus, causal conclusions could not be established. Responses provided by the students may have been subject to social desirability bias. However, this might have been mitigated by the online nature of the survey and by not collecting any identifiers.

In conclusion, the study validated the factor structure of the OMS-HC instrument, and it was used to examine stigma among healthcare students in Singapore. This scale could potentially be used, as with the intended purpose of the researchers to develop the scale, to evaluate future anti-stigma interventions within the local healthcare community. Though the level of stigma among healthcare students was generally low, there is room for improvement, particularly in the area of disclosure. Advocacy to reduce stigmatising attitudes towards mentally ill ought to be promoted by healthcare educators for these students while they are in training. They are the future healthcare professionals and their views and behaviours can greatly influence societal dispositions towards the mentally ill.

Contributors SC and HLO drafted the first version of the manuscript. ESe and BYC conceived the study and designed the study protocol. EA helped to carry out the analyses. ESa, WLT, SAC and MS critically reviewed the article and provided their inputs. All authors have read and approved the final manuscript.

Funding This work was supported by Singapore Ministry of Health's National Medical Research Council (NMRC) under its Centre Grant Programme (Grant No: NMRC/CG/004/2013). 
Disclaimer The funding body had no involvement in study design; in the collection,analysis and interpretation of data; in the writing of the report; and in the decision to submit the article for publication.

Competing interests None declared.

Ethics approval National Healthcare Group's Domain Specific Review Board, Singapore.

Provenance and peer review Not commissioned; externally peer reviewed.

Data sharing statement Data supporting the findings are available on request. Please contact MS (mythily@imh.com.sg) for data availability.

Open Access This is an Open Access article distributed in accordance with the Creative Commons Attribution Non Commercial (CC BY-NC 4.0) license, which permits others to distribute, remix, adapt, build upon this work non-commercially, and license their derivative works on different terms, provided the original work is properly cited and the use is non-commercial. See: http://creativecommons.org/ licenses/by-nc/4.0/

(C) Article author(s) (or their employer(s) unless otherwise stated in the text of the article) 2017. All rights reserved. No commercial use is permitted unless otherwise expressly granted.

\section{REFERENCES}

1. World Health Organization. World health report 2001 : mental health:new understanding, new hope. Albany: World Health Organization, 2001.

2. Yuan Q, Abdin E, Picco L, et al. Attitudes to mental illness and its demographic correlates among general population in Singapore. PLoS One 2016;11:e0167297.

3. Subramaniam M, Abdin E, Picco L, et al. Stigma towards people with mental disorders and its components - a perspective from multiethnic Singapore. Epidemiol Psychiatr Sci 2017;26:371-82.

4. Jorm AF, Korten AE, Jacomb PA, et al. Attitudes towards people with a mental disorder: a survey of the Australian public and health professionals. Aust N Z J Psychiatry 1999;33:77-83.

5. Moxham L, Taylor E, Patterson C, et al. Can a clinical placement influence stigma? An analysis of measures of social distance. Nurse Educ Today 2016;44:170-4.

6. Yamaguchi S, Wu SI, Biswas M, et al. Effects of short-term interventions to reduce mental health-related stigma in university or college students: a systematic review. J Nerv Ment Dis 2013;201:490-503.

7. Clement S, van Nieuwenhuizen A, Kassam A, et al. Filmed v. live social contact interventions to reduce stigma: randomised controlled trial. Br J Psychiatry 2012;201:57-64.

8. Corrigan PW, Druss BG, Perlick DA. The impact of mental illness stigma on seeking and participating in mental health care. Psychol Sci Public Interest 2014;15:37-70.

9. Brondani MA, Alan R, Donnelly L. Stigma of addiction and mental illness in healthcare: the case of patients' experiences in dental settings. PLoS One 2017;12:e0177388.

10. Happell B, Gaskin CJ, Byrne L, et al. Clinical placements in mental health: a literature review. Issues Ment Health Nurs 2015;36:44-51.

11 Friedrich B, Evans-Lacko S, London J, et al. Anti-stigma training for medical students: the education not discrimination project. $\mathrm{Br} J$ Psychiatry Suppl 2013;55:s89-94.

12. Thornicroft G, Rose D, Kassam A. Discrimination in health care against people with mental illness. Int Rev Psychiatry 2007;19:113-22.

13. Lauber C, Nordt C, Braunschweig C, et al. Do mental health professionals stigmatize their patients? Acta Psychiatr Scand Suppl 2006;113:51-9.

14. Mental Health Commission of Canada. Opening minds interim report. 2013. http://www.mentalhealthcommission.ca/sites/default/files/ opening_minds_interim_report_0.pdf (accessed 13 Mar 2017).

15. Pellegrini C. Mental illness stigma in health care settings a barrier to care. CMAJ 2014;186:E17.

16. Winkler $P$, Mladá $K$, Janoušková $M$, et al. Attitudes towards the people with mental illness: comparison between Czech medical doctors and general population. Soc Psychiatry Psychiatr Epidemiol 2016;51:1265-73.

17. Reavley NJ, Mackinnon AJ, Morgan AJ, et al. Stigmatising attitudes towards people with mental disorders: a comparison of Australian health professionals with the general community. Aust N Z J Psychiatry 2014;48:433-41.

18. Desforges DM, Lord CG, Ramsey SL, et al. Effects of structured cooperative contact on changing negative attitudes toward stigmatized social groups. J Pers Soc Psychol 1991;60:531-44.
19. Alexander $L$, Link $B$. The impact of contact on stigmatizing attitudes toward people with mental illness. J Ment Health 2003;12:271-89.

20. Henderson C, Robinson E, Evans-Lacko S, et al. Public knowledge, attitudes, social distance and reported contact regarding people with mental illness 2009-2015. Acta Psychiatr Scand 2016;134:23-33.

21. Nordt C, Rössler W, Lauber C. Attitudes of mental health professionals toward people with schizophrenia and major depression. Schizophr Bull 2006;32:709-14.

22. Hugo M. Mental health professionals' attitudes towards people who have experienced a mental health disorder. J Psychiatr Ment Health Nurs 2001;8:419-25.

23. Loch AA, Guarniero FB, Lawson FL, et al. Stigma toward schizophrenia: do all psychiatrists behave the same? Latent profile analysis of a national sample of psychiatrists in Brazil. BMC Psychiatry 2013;13:92.

24. Sullivan G, Mittal D, Reaves CM, et al. Influence of schizophrenia diagnosis on providers' practice decisions. J Clin Psychiatry 2015;76:1068-74.

25. Papish A, Kassam A, Modgill G, et al. Reducing the stigma of mental illness in undergraduate medical education: a randomized controlled trial. BMC Med Educ 2013;13:141.

26. Kassam A, Glozier N, Leese M, et al. Development and responsiveness of a scale to measure clinicians' attitudes to people with mental illness (medical student version). Acta Psychiatr Scand 2010;122:153-61.

27. Kassam A, Papish A, Modgill G, et al. The development and psychometric properties of a new scale to measure mental illness related stigma by health care providers: the Opening Minds Scale for Health Care Providers (OMS-HC). BMC Psychiatry 2012;12:62.

28. Gras LM, Swart M, Slooff CJ, et al. Differential stigmatizing attitudes of healthcare professionals towards psychiatry and patients with mental health problems: something to worry about? A pilot study. Soc Psychiatry Psychiatr Epidemiol 2015;50:299-306.

29. Poreddi V, Thimmaiah R, BadaMath S. National Institute of Mental health and Neurosciences. Medical and nursing students' attitudes toward mental illness: an Indian perspective. Investigación y Educación en Enfermería 2017;35:86-94.

30. Ewalds-Kvist B, Högberg T, Lützén K, et al. Student nurses and the general population in Sweden: trends in attitudes towards mental illness. Nord J Psychiatry 2013:67:164-70.

31. Poreddi V, Thimmaiah R, Pashupu DR, et al. Undergraduate nursing students' attitudes towards mental illness: implications for specific academic education. Indian J Psychol Med 2014;36:368-72.

32. James BO, Omoaregba JO, Okogbenin EO. Stigmatising attitudes towards persons with mental illness: a survey of medical students and interns from southern Nigeria. Ment IIIn 2012;4:e8.

33. Fernando SM, Deane FP, McLeod HJ. Sri Lankan doctors and medical undergraduates attitudes towards mental illness. Soc Psychiatry Psychiatr Epidemiol 2010;45:733-9.

34. Mahendran R, Lim HA, Verma SK, et al. Attitudes to psychiatry can change but what about stigma? Ann Acad Med Singapore 2014;43:473-4

35. Singapore Statistics. Population trends. 2017 http://www.singstat. gov.sg/publications/publications-and-papers/population-andpopulation-structure/population-trends (accessed 2 Aug 2017).

36. United States. Public Health Service, Office of the Surgeon General. Mental health: culture, race, and ethnicity : a supplement to mental health : a report of the surgeon general. Rockville, MD: U.S. Department of Health and Human Services, Substance Abuse and Mental Health Services Administration, Center for Mental Health Services, 2001.

37. Modgill G, Patten SB, Knaak S, et al. Opening minds stigma scale for health care providers (OMS-HC): examination of psychometric properties and responsiveness. BMC Psychiatry 2014;14:120.

38. Hayton JC, Allen DG, Scarpello V. Factor retention decisions in exploratory factor analysis: a tutorial on parallel analysis. Organ Res Methods 2004;7:191-205.

39. Kim J, Mueller CW. Factor analysis: statistical methods and practical issues. Vol. 07-014. Newbury Park, London: SAGE, 1978.

40. Asparouhov T, Muthén B. Exploratory structural equation modeling. Struct Equ Model 2009;16:397-438.

41. Marsh HW, Morin AJ, Parker PD, et al. Exploratory structural equation modeling: an integration of the best features of exploratory and confirmatory factor analysis. Annu Rev Clin Psychol 2014;10:85-110.

42. Guay F, Morin AJS, Litalien D, et al. Application of exploratory structural equation modeling to evaluate the academic motivation scale. J Exp Educ 2015;83:51-82.

43. Tabachnick BG, Fidell LS. Using multivariate statistics. Vol 6, International. Boston, London: Pearson, 2013. 
44. Serafini G, Pompili M, Haghighat R, et al. Stigmatization of schizophrenia as perceived by nurses, medical doctors, medical students and patients. J Psychiatr Ment Health Nurs 2011;18:576-85.

45. Yap MB, Mackinnon A, Reavley N, et al. The measurement properties of stigmatizing attitudes towards mental disorders: results from two community surveys. Int J Methods Psychiatr Res 2014;23:49-61.

46. Cleary A, Dowling M. Knowledge and attitudes of mental health professionals in Ireland to the concept of recovery in mental health: a questionnaire survey. J Psychiatr Ment Health Nurs 2009;16:539-45.

47. Rushworth L, Happell B. 'Psychiatric nursing was great, but I want to be a "real" nurse': is psychiatric nursing a realistic choice for nursing students? Aust N Z J Ment Health Nurs 2000;9:128-37.

48. Arvaniti A, Samakouri M, Kalamara E, et al. Health service staff's attitudes towards patients with mental illness. Soc Psychiatry Psychiatr Epidemiol 2009;44:658-65.

49. Cohen D, Winstanley SJ, Greene G. Understanding doctors' attitudes towards self-disclosure of mental ill health. Occup Med 2016;66:383-9.

50. Moll S, Eakin JM, Franche RL, et al. When health care workers experience mental ill health: institutional practices of silence. Qual Health Res 2013;23:167-79.
51. Joyce $T$, McMillan M, Hazelton M. The workplace and nurses with a mental illness. Int J Ment Health Nurs 2009;18:391-7.

52. Reavley NJ, Morgan AJ, Jorm AF. Disclosure of mental health problems: findings from an Australian National Survey. Epidemiol Psychiatr Sci 2017;19:1-11.

53. Golberstein E, Eisenberg D, Gollust SE. Perceived stigma and mental health care seeking. Psychiatr Serv 2008;59:392-9.

54. Bte Abd Malik NN, Kannusamy P, Klanin-Yobas P. The effectiveness of mental health-related theoretical education and clinical placement in mental health settings in changing the attitudes of health care students towards mental illness: a systematic review. JBI Libr Syst Rev 2012;10:4019-76.

55. Lyons Z, Janca A. Impact of a psychiatry clerkship on stigma, attitudes towards psychiatry, and psychiatry as a career choice. BMC Med Educ 2015;15:34

56. Henderson S, Happell B, Martin T. So what is so good about clinical experience? A mental health nursing perspective. Nurse Educ Pract 2007;7:164-72.

57. Happell B, Gaskin CJ. The attitudes of undergraduate nursing students towards mental health nursing: a systematic review. J Clin Nurs 2013;22:148-58. 